\title{
Critérios projetuais para cozinhas centrados nas necessidades dos idosos a partir da aplicação da metodologia de Design Thinking
}

Project criteria for kitchens focused on the needs of the elderly from the application of the methodology of Design Thinking

BEZ BATTI, Camila Arcaro; Bacharel em Design; Universidade Federal de Santa Catarina camilabezbatti@gmail.com

CAVALCANTI, Patrícia Biasi; Doutora em Arquitetura; Universidade Federal de Santa Catarina patibiasi@yahoo.com

\section{Resumo}

Neste trabalho teve-se por objetivo o desenvolvimento de critérios projetuais para o planejamento de cozinhas residenciais que sejam responsivas às características e necessidades dos idosos. O estudo fundamenta-se em revisão de literatura e na aplicação de métodos da linha do Design Thinking incluindo: Pesquisa Desk, Observação direta e sistemática, Entrevistas, Poema dos Desejos e Avaliação Antropométrica. Dentre os resultados, foi recorrente a importância de assegurar ao usuário idoso: conforto, demandando menos força física e evitando posturas inadequadas na realização das atividades cotidianas; segurança, minimizando riscos e proporcionando autonomia; legibilidade de cada componente do mobiliário, por meio de contrastes de cores, texturas e volumetrias; e funcionalidade, ao maximizar a capacidade de armazenagem desse ambiente. A incorporação desses atributos ao planejamento de cozinhas poderá contribuir para que elas sejam não apenas mais ajustadas às necessidades de idosos, como também de outros perfis de usuários.

Palavras Chave: terceira idade; cozinha; design thinking e usuário.

\begin{abstract}
In this work, the purpose was to develop design criteria for the planning of residential kitchens that are responsive to the characteristics and needs of the elderly. The study is based on literature review and the application of methods of the line of Design Thinking including: Desk Research, Direct and Systematic Observation, Interviews, Wish Poems and Anthropometric Evaluation. Among the results, it was recurrent the importance of assuring the elderly user: comfort, demanding less physical strength and avoiding inappropriate postures in the accomplishment of daily activities; safety, minimizing risks and providing autonomy; legibility of each component of the furniture, through contrasts of colors, textures and volumetrics; functionality by maximizing the storage capacity of that environment. The incorporation of these attributes into the planning of kitchens may contribute to their adaptation not only to the needs of the elderly, but also to other user profiles.
\end{abstract}

Keywords: third age; kitchen; design thinking and user. 


\section{Introdução}

A longevidade da população brasileira aumentou ao longo dos últimos anos. De 1940 a 2015, a expectativa de vida média se elevou consideravelmente para ambos os sexos, passando de 45,5 para 75,5 anos (PORTAL BRASIL, 2016). A taxa de natalidade tem progressivamente reduzido fazendo com que o percentual de crianças e adolescentes que correspondia a $42,6 \%$ da população em 1940 seja estimado em 14,1\% para 2050 (OLIVEIRA, 2016 apud FIGUEIREDO, 2016). Em paralelo houve um aumento na proporção de pessoas idosas, cujo percentual era de apenas 4,1\% da população em 1940, passando a ser estimado em $29,4 \%$ para 2050 . Atualmente os idosos representam $12,1 \%$ do total da população brasileira, correspondendo a cerca de 25 milhões de pessoas, sendo consideradas idosas aquelas com idade igual ou superior a sessenta anos segundo o Estatuto do Idoso (SENADO FEDERAL, 2003).

De acordo com o Serviço de Proteção ao Crédito - SPC - (2016) os idosos são os principais responsáveis por suas decisões de compras, pois boa parcela deles tem autonomia, tempo e dinheiro para decidir com o que gastar. No entanto, nem sempre eles encontram produtos e serviços específicos para as suas necessidades, o que sugere que o mercado ainda não está plenamente preparado para atender esta crescente demanda.

Algumas mudanças fisiológicas decorrem do processo de envelhecimento e impactam na utilização de produtos, serviços e ambientes por este público. Tais mudanças podem incluir, por exemplo: decréscimo de força física, perda de mobilidade, falta de atenção, perda de equilíbrio, alterações na visão e na audição, reações mais lentas, dentre outras (CHRISTENSON, 1990). A presença de um ou mais desses fatores faz com que aumente a probabilidade de queda na terceira idade, sendo este o acidente mais frequente para esta faixa etária (DRECH; POMATTI; DORING, 2009). Segundo o Ministério da Saúde (2006) cerca de $30 \%$ dos idosos cai a cada ano, e esse número aumenta para $40 \%$ se considerarmos apenas os idosos com mais de 80 anos. As mulheres tendem a cair com mais frequência se comparadas aos homens com até 75 anos de idade; após esta idade a frequência de quedas se iguala. Além de serem muito frequentes, as quedas podem ter consequências graves, visto que são responsáveis por $90 \%$ das fraturas de quadris em idosos (DRECH; POMATTI; DORING, 2009 apud ABRAMS; BERKOW, 1994). Agravando este quadro, tem-se o fato de que os idosos tendem a ter um processo de recuperação da saúde mais lento, de modo que tais acidentes costumam ter um impacto maior neste grupo etário do que em outros.

Dentro do ambiente residencial, os dois locais onde há maior ocorrência de acidentes são a cozinha e o banheiro (DRECH; POMATTI; DORING, 2009). Por este motivo, tais ambientes precisam ser cuidadosamente planejados. Além disso, destaca-se a importância do papel desempenhado pela cozinha no contexto residencial, como menciona lida (2005, p. 564):

\footnotetext{
Diversas pesquisas demonstram que a cozinha é o lugar mais importante da casa e ela cresce de importância em famílias de menor renda. Ela é praticamente um centro de produção de alimentos, e está ocupada durante o dia todo. É na cozinha que ocorrem cerca de $50 \%$ dos encontros familiares e muitas famílias preferem tomar as suas refeições na própria cozinha.
}

Apesar de sua relevância, há escassez de trabalhos científicos no Brasil que identifiquem as necessidades específicas do público idoso relativas ao planejamento do ambiente residencial, e mais especificamente de cozinhas. Neste sentido, busca-se no presente trabalho contribuir para a discussão do tema, identificando critérios projetuais relevantes para o planejamento de cozinhas 
destinadas a esse público. Como objetivos secundários pretende-se compreender: quais as necessidades, anseios e características deste público específico que vão impactar na vivência da cozinha; e quais os atributos desejáveis ao ambiente para a sua adequação. Para tanto, optou-se por realizar um estudo de natureza qualitativa e exploratória, utilizando a metodologia de Design Thinking de forma que os métodos adotados e os resultados obtidos fossem centrados nos usuários.

\section{Fundamentação Teórica}

A vivência de um indivíduo em um determinado ambiente está diretamente relacionada às características do ambiente, pois este pode ser um facilitador ou um dificultador das atividades que nele serão realizadas. Idosos em geral tendem a permanecer por mais tempo no ambiente residencial, tornando ainda mais importante a sua adequação para as atividades cotidianas e para a sua qualidade de vida. Assim, planejar o ambiente residencial de forma adaptada às mudanças que ocorrem com o envelhecimento é crucial para que a pessoa mais velha possa usufruir ao máximo da sua competência e autonomia (CHRISTENSON, 1990). Planejar adaptações pequenas e gradativas do ambiente visando acompanhar as necessidades reais dos idosos à medida que se manifestam é uma tarefa simples e que pode ser executada sem um grande esforço material ou emocional do usuário. A atuação do projetista - designer, arquiteto ou engenheiro - neste cenário demanda uma compreensão do processo de envelhecimento e das necessidades espaciais dele decorrentes (FRANK, 2003). E, para tanto, faz-se necessário compreender também aspectos relativos à antropometria e à biomecânica que impactam na utilização do ambiente da cozinha pelo idoso.

Antropometria é a ciência que trata especificamente do estudo das medidas do corpo humano, e sua aplicação no âmbito da Ergonomia visa dar suporte ao planejamento de objetos e ambientes que estejam adequados às dimensões corporais de seus usuários (PANERO; ZELNIK, 2002; IIDA, 2005; DUL; WEERDMEESTER, 2004). Já a biomecânica refere-se ao estudo das leis físicas da mecânica aplicadas ao corpo humano. Estudam-se movimentos, posturas corporais e força aplicada na realização de tarefas, buscando compreender sua relação com os sistemas biológicos, e no âmbito da Ergonomia, busca-se direcionar esse conhecimento ao planejamento de objetos e ambientes que reduzam as tensões, dores e lesões em seus usuários (DUL; WEERDMEESTER, 2004; IIDA, 2005; AMADIO; SERRÃO, 2007).

Durante o processo de envelhecimento tendem a ocorrer perdas gradativas de: massa muscular, estrutura óssea, elasticidade das cartilagens, flexibilidade das articulações, além da diminuição das medidas corporais e do alcance dos idosos. Tudo isso, contribui para tornar os movimentos musculares mais fracos e lentos, e com menor amplitude, impactando na redução da força física e da mobilidade. O envelhecimento também tende a causar perdas progressivas relativas à função cardiovascular, aos órgãos dos sentidos e à função cerebral (IIDA, 2005; HAYFLICK, 1997; MATSUDO; BARROS, 2000; FECHINE; TROMPIERI, 2012).

No que se refere especificamente a antropometria, uma vez que existem diferenças significativas entre as medidas de cada pessoa e mesmo entre as medidas de indivíduos de um mesmo grupo de usuários potenciais, não se recomenda projetar considerando-se apenas dimensões corporais medianas. Ao se planejar ambientes para pessoas com dimensões medianas, se estão desconsiderando todos os indivíduos que possuem dimensões superiores ou inferiores as mesmas. Além disso, mesmo um usuário idoso que possa ter uma altura considerada média, pode 
apresentar outras dimensões corporais acima ou abaixo das médias. Deste modo, o ideal é projetar considerando sempre as situações mais desfavoráveis, de forma a adequar o espaço e o mobiliário à grande maioria dos usuários (PANERO; ZELNIK, 2002; IIDA, 2005).

Alguns aspectos considerados importantes para a adequação de qualquer tipo de posto de trabalho aos seus usuários (IIDA, 2005; DUL; WEERDMEESTER, 2004) incluem: altura, largura e profundidade da superfície de trabalho; alcances recomendados e máximos das mãos; espaço para acomodar os pés e as pernas; espaço para realizar movimentações laterais do corpo; posicionamento das áreas preferenciais de trabalho dentro do campo de visão do usuário; minimizar a ocorrência de atividades acima do nível dos ombros; e evitar que seja necessário trabalhar com as mãos para trás.

No caso específico do projeto de uma cozinha cabe destacar alguns aspectos importantes a serem considerados como: a altura e a profundidade da bancada de trabalho, a altura e a profundidade do móvel suspenso, os espaços livres para circulação entre os móveis e os eletrodomésticos grandes, o acesso visual e físico às bancadas e aos armários. Além disso, é importante ponderar sobre a frequência dos movimentos no ambiente da cozinha. Diversos estudos demonstram que a maior movimentação ocorre entre a bancada e a pia, e entre a bancada e o fogão, havendo uma demanda menor entre bancada e a geladeira e a bancada e o armário. Como se vê, a bancada funciona sempre como o centro irradiador desses movimentos, tornando fundamental o seu planejamento cuidadoso (IIDA, 2005).

Também é necessário estudar as posturas que são realizadas ao longo do dia pelas pessoas em suas atividades na cozinha. Procura-se planejar os móveis de forma a favorecer a adoção de posturas neutras, ou seja, aquelas que impõem a menor carga possível sobre as articulações e segmentos musculoesqueléticos (RIO; PIRES, 2001). É importante prevenir as dores lombares, sendo essencial que, no posto de trabalho, possam ser exercidas as atividades com o dorso na vertical, tanto na postura em pé como na sentada. Observam-se, por exemplo, erros frequentes no dimensionamento da altura das bancadas, no caso específico da cozinha (IIDA, 2005; DUL; WEERDMEESTER, 2004).

A posição sentada é a menos cansativa para a execução de tarefas em geral. Porém, de qualquer modo, devem-se evitar longos períodos em uma mesma posição e planejar um ambiente e mobiliário que favoreça sua alternância - sentada, em pé e andando. Algumas atividades realizadas na posição sentada exigem um acompanhamento visual maior, o que faz com que a cabeça e o corpo se inclinem para frente. Períodos muito longos nessa posição podem causar dores e tensões no pescoço e nas costas. Mesmo as tarefas que exigem muito tempo em pé, como a preparação de refeições devem ser alternadas com a posição sentada com o auxílio de banco ou cadeira (RIO; PIRES, 2001).

As manipulações fora do alcance dos braços exigem movimentos do tronco e também podem causar tensões no corpo. Assim, as atividades mais importantes e frequentes devem preferencialmente ser realizadas dentro de um raio aproximado de 50 centímetros a partir da articulação entre os braços e os ombros do usuário. Deve-se evitar realizar atividades que necessitem que as mãos e os cotovelos fiquem acima do nível dos ombros. lida (2005) menciona que, quando o braço é mantido em posição elevada, acima da altura dos ombros, os músculos dos ombros e do bíceps fadigam-se rapidamente, e podem aparecer dores especialmente nos idosos, que muitas vezes tem as articulações debilitadas. O planejamento do ambiente também deve 
considerar que os alcances com os braços para frente e para os lados sejam limitados, evitando demandar a inclinação do corpo com muita frequência (DUL; WEERDMEESTER, 2004).

A altura da superfície de trabalho deve ser determinada de forma a adequar-se a uma altura confortável para as mãos e a melhor posição para os olhos, definindo assim a postura da cabeça e do tronco do usuário (DUL; WEERDMEESTER, 2004). Em relação ao sistema óptico, o que se busca é a adequação da zona visual de atenção, colocando os componentes que precisam ser observados numa posição que facilite sua visualização pelo usuário e que não demande posturas e movimentos inadequados (RIO; PIRES, 2001).

As mudanças que decorrem do envelhecimento também incluem perdas relativas aos sensores táteis. Por isso, deve-se ter especial atenção para as posições de pega das mãos, elas influenciam na escolha ou projeto dos tipos de puxadores utilizados na cozinha, por exemplo (RIO; PIRES, 2001).

Os conhecimentos da antropometria e da biomecânica são certamente fundamentais para que seja possível planejar ambientes mais adequados aos diversos públicos usuários, incluindo os idosos. Observa-se que alguns princípios gerais, que não são específicos de estudos direcionados a terceira idade, seguem sendo importantes no planejamento de ambientes também para esse público, como por exemplo, priorizar posturas neutras. Por outro lado, estudos futuros das medidas corporais do idoso brasileiro e avaliações sistemáticas de cozinhas residenciais certamente contribuiriam muito para a orientação de projetos mais ajustados às suas características. É importante que o ambiente e o mobiliário adequem-se ao usuário da terceira idade, pois assim minimizam-se riscos de acidentes, e se oferecem conforto, autonomia e independência.

\section{Metodologia}

A abordagem metodológica adotada baseia-se no Design Thinking (VIANNA et al., 2012), por estar centrada no usuário, suas necessidades e anseios e por oferecer uma grande variedade de métodos distintos para aprofundamento de um tema específico. Dentre os métodos possíveis de serem aplicados, optou-se por realizar: pesquisa Desk, Observação direta e sistemática, Entrevistas, Poema dos Desejos e Avaliação Antropométrica, descritos brevemente a seguir. Cabe observar que o Poema dos Desejos e a Avaliação Antropométrica não são métodos típicos de Design Thinking, mas que se adequam a essa abordagem metodológica, já que também estão centrados nos usuários.

A pesquisa Desk (VIANNA et al., 2012) corresponde à revisão bibliográfica e no contexto deste estudo, foi realizada na área de Ergonomia, sobretudo relacionando-se a Antropometria e Biomecânica do usuário. Buscou-se com a revisão bibliográfica estudar os seguintes tópicos: perfil do usuário idoso, mudanças fisiológicas que decorrem do envelhecimento, orientações gerais para planejamento de postos de trabalho, aspectos antropométricos e biomecânicos relacionados às atividades realizadas na cozinha, e análise de projetos similares - projetos de cozinhas que se baseiem em princípios de Desenho Universal ${ }^{1}$ ou que estejam direcionados ao público idoso.

Foram realizadas observações diretas e sistemáticas (RHEINGANTZ, 2009) de idosos utilizando o ambiente da cozinha de suas respectivas casas. Objetivou-se compreender: suas

\footnotetext{
${ }^{1}$ Desenho Universal: é o processo de criar produtos que são acessíveis para todas as pessoas, independente de suas características pessoais, idade, ou habilidades (CAMBIAGHI, 2012).
} 
atividades, rotinas, necessidades e características, possíveis constrangimentos e padrões comportamentais na relação do usuário com o local. Foram observadas duas idosas, uma com 60 anos e a outra com 81 anos ao longo de todo o processo de preparo de uma refeição. As observações foram centradas no ambiente e, portanto a pesquisadora ficou parada no local registrando o que via de forma menos intrusiva possível. Os registros foram feitos de modo escrito e por fotografias, duraram cerca de uma hora em cada ambiente analisado.

As entrevistas foram realizadas através de dois roteiros semiestruturados, a fim de compreender alguns temas específicos. Primeiramente, foi entrevistado um geriatra com o intuito de entender quais as principais características do idoso que impactam diretamente na vivência do ambiente e suas necessidades espaciais, do ponto de vista de um médico. Em seguida, também foram feitas entrevistas com dois projetistas - arquitetos - de grandes empresas de móveis planejados, visando compreender seu nível de entendimento sobre as necessidades da terceira idade, suas experiências prévias com planejamento de móveis para esse público específico, e como está sendo pensado o mercado de móveis para esse segmento.

Em seguida foi aplicado o Poema dos Desejos (SANOFF, 1990), método este criado por Henry Sanoff para projetos participativos, e que consiste em compreender as expectativas, anseios e desejos dos usuários em relação ao ambiente. O método foi aplicado com 15 (quinze) idosos. Foi entregue um formulário em branco introduzindo o que era a pesquisa, com destaque para a seguinte frase: "Eu gostaria que o projeto de uma cozinha fosse ou tivesse...". O participante era então convidado para expressar livremente o que ele acreditava ser desejável para o ambiente da cozinha por meio de desenhos ou de textos. Como o método não direciona nenhum tipo de resposta, ele favorece a compreensão de aspectos importantes ou desejáveis para o local no ponto de vista dos usuários.

Por fim, desenvolveu-se a Avaliação Antropométrica de uma cozinha hipotética, elaborada com base em todos os resultados dos métodos anteriores, de forma a checá-los. A avaliação foi feita através do software AutoCAD, com a inserção de um manequim antropométrico que continha as medidas corporais do público idoso, verificando a adequação do ambiente em relação a algumas medidas como, alcance vertical e frontal, altura da bancada, largura corporal referente ao espaço destinado ao cadeirante, entre outras. Foram utilizadas medidas antropométricas para planejamento de cozinhas, presentes na revisão de literatura como critérios dessa avaliação.

Os resultados dos métodos aplicados foram tratados qualitativamente, buscando-se descrever as principais necessidades e anseios desse público, e também constrangimentos observados na vivência do ambiente. Além dos relatos descritivos mais detalhados, também se utilizou Análise de Conteúdo (BARDIN, 2011), e, para tanto, foram criadas categorias de resultados afins e recorrentes, referentes aos atributos desejáveis ao planejamento da cozinha para o idoso, sendo eles: conforto, segurança, legibilidade e funcionalidade.

\section{Resultados e Discussão}

Após tratados e descritos separadamente os resultados de cada método, foi realizada uma tabela síntese de todos eles (Tabela 1), visando dar suporte à análise comparativa.

Nessa tabela, focou-se nos resultados obtidos com os métodos centrados nos usuários. Assim, não foram incluídos abaixo os dados obtidos na pesquisa desk, com a revisão de literatura e a análise de similares. Parte dos resultados obtidos com os métodos centrados nos usuários 
aponta diretamente para diretrizes projetuais a serem consideradas no planejamento de cozinhas para idosos. Outra parte dos resultados aponta para constrangimentos verificados na vivência da cozinha pelo idoso. Nesses casos, o conhecimento obtido com a revisão de literatura e análise de similares deu suporte à posterior elaboração das diretrizes projetuais que poderiam contribuir para eliminar os constrangimentos identificados.

Tabela 1 - Síntese dos principais resultados de cada método aplicado.

\begin{tabular}{|c|c|c|c|c|}
\hline \multirow{2}{*}{$\begin{array}{c}\text { ATRIBUTO } \\
\text { AMBIENTAL } \\
\text { RELACIONADO } \\
\text { AOS RESULTADOS }\end{array}$} & \multicolumn{4}{|c|}{ PRINCIPAIS RESULTADOS } \\
\hline & OBSERVAÇÃO & ENTREVISTAS & POEMA DOS DESEJOS & $\begin{array}{l}\text { AVALIAÇÃO } \\
\text { ANTROPOMÉTRICA }\end{array}$ \\
\hline \multirow[t]{2}{*}{$\begin{array}{l}\text { Conforto } \\
\text { (alcance frontal e } \\
\text { vertical, postura } \\
\text { neutra) }\end{array}$} & $\begin{array}{c}\text { Dificuldade de } \\
\text { alcance vertical e } \\
\text { frontal de alguns } \\
\text { utensílios; } \\
\text { Necessidade de se } \\
\text { apoiar no móvel } \\
\text { para alcance de } \\
\text { objetos nas } \\
\text { prateleiras mais } \\
\text { baixas; } \\
\text { - }\end{array}$ & $\begin{array}{l}\text { Planejar a área de } \\
\text { trabalho entre a } \\
\text { altura da cintura e } \\
\text { do tórax, } \\
\text { facilitando o } \\
\text { alcance; }\end{array}$ & $\begin{array}{l}\text { O mobiliário não pode } \\
\text { ser nem muito alto, } \\
\text { nem muito baixo; }\end{array}$ & $\begin{array}{l}\text { Prever altura de cerca de } 55 \\
\text { cm entre a bancada de } \\
\text { trabalho e o móvel suspenso. } \\
\text { Para cadeirante, recomenda- } \\
\text { se } 45 \mathrm{~cm} \text {; } \\
\text { Prever que móveis e } \\
\text { prateleiras mais altas possam } \\
\text { ser abaixados; } \\
\text { Prever prateleiras retráteis, } \\
\text { sempre que possível, } \\
\text { facilitando o alcance físico e } \\
\text { visual a todos os objetos; }\end{array}$ \\
\hline & - & - & - & $\begin{array}{l}\text { Prever rodapé que favoreça a } \\
\text { aproximação ao móvel, com } \\
\text { altura mínima de } 7,5 \mathrm{~cm} \mathrm{e} \\
\text { recuo de } 10 \mathrm{~cm} ;\end{array}$ \\
\hline $\begin{array}{c}\text { Conforto } \\
\text { (demandar menos } \\
\text { força física) }\end{array}$ & $\begin{array}{l}\text { Dificuldade para } \\
\text { fechar gavetas; }\end{array}$ & - & $\begin{array}{l}\text { Gavetas devem ser } \\
\text { leves, mas sem } \\
\text { amortecimento, pois } \\
\text { este demanda mais } \\
\text { força para abrir; }\end{array}$ & $\begin{array}{l}\text { Utilizar corrediças que } \\
\text { facilitem a abertura de } \\
\text { gavetas e prateleiras; }\end{array}$ \\
\hline $\begin{array}{c}\text { Conforto } \\
\text { (acuidade visual) }\end{array}$ & $\begin{array}{l}\text { Não há iluminação } \\
\text { específica } \\
\text { direcionada para a } \\
\text { área de trabalho; }\end{array}$ & $\begin{array}{c}\text { Assegurar } \\
\text { condições } \\
\text { adequadas de } \\
\text { iluminação para } \\
\text { tarefas de grande } \\
\text { acuidade visual; } \\
\end{array}$ & $\begin{array}{c}\text { Priorizar uma } \\
\text { iluminação mais intensa } \\
\text { na cozinha; }\end{array}$ & - \\
\hline $\begin{array}{c}\text { Conforto } \\
\text { (acessibilidade) }\end{array}$ & - & $\begin{array}{l}\text { Planejar ambiente } \\
\text { com circulações } \\
\text { adequadas à } \\
\text { mobilidade e à } \\
\text { acessibilidade; }\end{array}$ & - & $\begin{array}{c}\text { Deve-se prever vão livre } \\
\text { mínimo de } 80 \mathrm{~cm} \text { de largura } \\
\text { sob a bancada da pia para o } \\
\text { encaixe do cadeirante ou de } \\
\text { uma cadeira para trabalho na } \\
\text { posição sentada; }\end{array}$ \\
\hline
\end{tabular}




\begin{tabular}{|c|c|c|c|c|}
\hline $\begin{array}{c}\text { Segurança } \\
\text { (minimizar risco e } \\
\text { impacto de } \\
\text { acidentes) }\end{array}$ & $\begin{array}{l}\text { Presença de cantos } \\
\text { vivos nos móveis; } \\
\text { Não há barras de } \\
\text { apoio; }\end{array}$ & $\begin{array}{l}\text { Dar preferência a } \\
\text { cantos } \\
\text { arredondados no } \\
\text { mobiliário; } \\
\text { Prever barras de } \\
\text { apoio na cozinha; }\end{array}$ & - & $\begin{array}{l}\text { Posicionar forno micro-ondas } \\
\text { e forno elétrico na zona } \\
\text { preferencial de trabalho } \\
\text { (altura entre a cintura e os } \\
\text { ombros); }\end{array}$ \\
\hline & - & - & - & $\begin{array}{c}\text { Prever prateleira retrátil para } \\
\text { apoio dos pratos quentes } \\
\text { logo abaixo do(s) forno(s); }\end{array}$ \\
\hline Legibilidade & $\begin{array}{c}\text { Presença de } \\
\text { poucas cores no } \\
\text { mobiliário e } \\
\text { ausência de } \\
\text { contrastes; }\end{array}$ & $\begin{array}{l}\text { Explorar o uso de } \\
\text { cores no design do } \\
\text { mobiliário para } \\
\text { maior legibilidade; }\end{array}$ & $\begin{array}{l}\text { Dar preferência a cores } \\
\text { claras no mobiliário; }\end{array}$ & - \\
\hline Funcionalidade & - & - & $\begin{array}{l}\text { Prever bastante área de } \\
\text { armazenamento na } \\
\text { cozinha; }\end{array}$ & - \\
\hline
\end{tabular}

Fonte: das autoras (2018)

Boa parte dos resultados está relacionada ao conforto do usuário, visando proporcionar condições favoráveis para a realização das tarefas cotidianas no ambiente da cozinha, demandando o mínimo possível de força física e de posturas inadequadas do usuário idoso. Estes resultados incluem aspectos relativos a: favorecer a adoção de uma postura neutra, facilitar os alcances vertical e frontal, demandar menos força física, favorecer a acuidade visual e a acessibilidade. Observa-se que, boa parte dos aspectos apontados pelos participantes ou constatados pelos pesquisadores, relaciona-se as áreas de ergonomia - antropometria e biomecânica. Ao serem considerados nas etapas de planejamento e projeto do ambiente tais aspectos podem contribuir para evitar fadiga e lesões, favorecendo o bem-estar dos usuários.

Outro atributo bastante recorrente nos resultados é a segurança. O conceito de segurança refere-se aos aspectos do ambiente e do mobiliário que minimizem o risco de acidentes e lesões de maior gravidade, já que a cozinha é um dos ambientes da residência onde eles ocorrem com maior frequência. Em relação a esse aspecto, busca-se identificar locais ou componentes potencialmente perigosos, tentando através do projeto eliminar ou reduzir os danos que os mesmos poderiam causar. Dentre os resultados incluem-se: aspectos relativos ao arredondamento das superfícies, para que, em caso de queda, o idoso não se corte; a disponibilidade de barras de apoio em pontos estratégicos da cozinha; e o posicionamento dos fornos na zona preferencial de trabalho (entre a cintura e os ombros), bem como a previsão de superfícies fixas ou retráteis sob eles para que se possam apoiar pratos quentes.

O terceiro atributo ambiental constatado nos resultados é a legibilidade. Com o envelhecimento ocorrem diversas mudanças fisiológicas e cognitivas que poderão comprometer a acuidade visual, tornando mais difícil para o usuário idoso identificar a profundidade, os limites e as formas dos objetos, além de não conseguir diferenciar algumas cores. Também tendem a ocorrer perdas cognitivas que tornarão mais difícil memorizar a posição de determinados objetos dentro da cozinha ou identificar a função a que se destinam componentes dos móveis ou do 
ambiente. O planejamento de ambientes explorando diferentes cores, texturas e formas, bem como o contraste entre eles, pode contribuir para sua maior adequação às necessidades e habilidades dos usuários.

Por fim, durante a aplicação do Poema dos Desejos junto ao público idoso, destacou-se o anseio por criar a maior quantidade possível de áreas de armazenamento (armários, estantes, gavetas, etc.) dentro da cozinha. Esse anseio dos usuários relaciona-se, sobretudo à busca pela funcionalidade no ambiente da cozinha e pode estar relacionado ao fato de que as residências urbanas tendem a ser cada vez mais compactas, demandando um planejamento cuidadoso dos ambientes para que sejam mais bem aproveitados. Maximizar a área de armazenamento possivelmente não é um anseio exclusivo do público idoso, nem se relaciona especificamente ao processo de envelhecimento. Além disso, esse atributo ambiental foi apontado em apenas um dos métodos aplicados. A despeito disso, optou-se por incorporá-lo a lista de atributos desejáveis por ter se mostrado um aspecto recorrente e muito importante na percepção dos usuários participantes durante a aplicação do Poema dos Desejos.

\section{Diretrizes projetuais}

Ao se projetar ambientes para pessoas idosas, devemos estar conscientes de que a competência é afetada por muitos fatores psicológicos e sociais. Esses fatores menos tangíveis relacionam-se as características do ambiente que devem ser atendidas para realmente permitir que uma pessoa envelheça com qualidade na sua residência. Essas características foram descritas como atributos ambientais (CHRISTENSON, 1990 apud WINDLEY; SCHEIDT, 1980), que atribuem um componente social e físico a um determinado item ou local.

A partir da análise comparativa dos resultados foram sintetizadas diretrizes e alternativas projetuais relacionadas aos principais atributos desejáveis ao ambiente da cozinha. Assim, na tabela 2 encontrada abaixo, são relacionadas as diretrizes e alternativas projetuais com os atributos ambientais a que se referem e também com os métodos que permitiram identificá-las.

Como mencionado anteriormente, boa parte das diretrizes projetuais foram apontadas pelos participantes do estudo, a partir dos resultados obtidos na aplicação dos métodos. Outras se baseiam em publicações sobre o tema, consultadas durante a revisão de literatura ou em projetos de cozinhas disponíveis online, estudados por meio da análise de similares, e que apresentavam soluções projetuais voltadas para esse público usuário. 
Tabela 2 - Síntese dos principais atributos desejáveis ao ambiente e diretrizes projetuais resultantes.

\begin{tabular}{|c|c|}
\hline $\begin{array}{l}\text { MÉTODOS EM QUE FORAM } \\
\text { EVIDENCIADOS }\end{array}$ & DIRETRIZES PROJETUAIS \\
\hline $\begin{array}{c}\text { Pesquisa Desk } \\
\text { Obs. direta e sistemática } \\
\text { Entrevista } \\
\text { Poema dos Desejos } \\
\text { Avaliação Antropométrica }\end{array}$ & 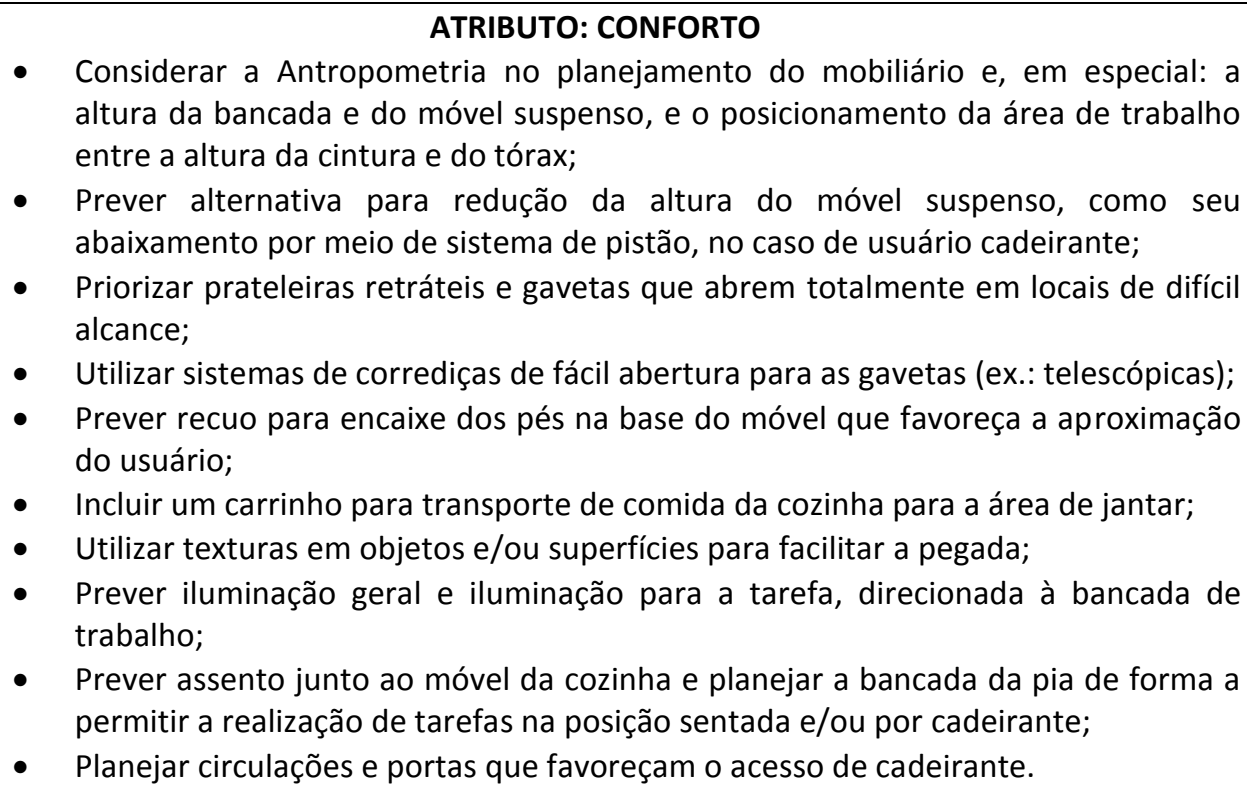 \\
\hline $\begin{array}{l}\text { Pesquisa Desk } \\
\text { Obs. direta e sistemática } \\
\text { Entrevista } \\
\text { Poema dos Desejos }\end{array}$ & $\begin{array}{l}\text { ATRIBUTO: SEGURANÇA } \\
\text { - Dar preferência a acabamentos arredondados ou protegidos para móveis e } \\
\text { - } \quad \text { Utilizar materiais resistentes no móvel, puxadores aparafusados e barras de } \\
\text { apoio; } \\
\text { - Posicionar fornos na altura entre a cintura e os ombros e prever suportes } \\
\text { - } \text { retráteis próximos a eles para apoiar pratos quentes; } \\
\text { - Prever alerta sonoro e visual para vazamento de gás e fumaça; } \\
\text { Prever proteção frontal junto a prateleiras, evitando que objetos caiam sobre o } \\
\text { usuário. }\end{array}$ \\
\hline $\begin{array}{l}\text { Pesquisa Desk } \\
\text { Obs. direta e sistemática } \\
\text { Entrevista } \\
\text { Poema dos Desejos }\end{array}$ & $\begin{array}{l}\text { ATRIBUTO: LEGIBILIDADE } \\
\text { - } \quad \text { Prever contrastes de formas, cores e texturas no mobiliário e no ambiente; } \\
\text { - Evitar o uso conjunto de algumas cores de difícil distinção no mobiliário e no } \\
\text { ambiente; } \\
\text { - Utilizar recursos de comunicação visual, como sinalização em braile no caso de } \\
\text { usuário cego, ou imagens no caso de usuário com perda de memória. }\end{array}$ \\
\hline Poema dos Desejos & $\begin{array}{l}\text { ATRIBUTO: FUNCIONALIDADE } \\
\text { - Maximizar a área de armazenamento de utensílios, objetos e suprimentos na } \\
\text { cozinha. }\end{array}$ \\
\hline
\end{tabular}

Fonte: das autoras (2018)

O conforto do usuário foi um atributo desejável ao ambiente evidenciado em todos os métodos. Assim, boa parte das diretrizes e alternativas projetuais se refere a ele. Dentre elas foram mencionadas: o dimensionamento de cada componente da cozinha com base na Antropometria, destacando-se a importância do planejamento da altura da bancada e do móvel suspenso, e do posicionamento da área de trabalho em relação à altura máxima entre a cintura e o tórax do idoso; em caso de usuário cadeirante, prever ferragens que permitam reduzir a altura do móvel suspenso como, por exemplo, um sistema de pistão que permita abaixá-lo; dentro dos armários, dar preferência à instalação de prateleiras, gavetas e outros recursos com corrediças 
que permitam trazê-los totalmente para fora do móvel, facilitando o alcance aos objetos posicionados no fundo; incorporar sistemas de corrediças que facilitem a abertura das gavetas, como as telescópicas; explorar texturas nos objetos e/ou mobiliário para facilitar a pegada; prever no ambiente um carrinho que auxilie no transporte dos alimentos e que sirva como apoio ao deslocamento do idoso; prever locais para encaixe de cadeira de rodas ou cadeira convencional sob a bancada, especialmente da pia, permitindo ao idoso alternar entre a posição em pé e sentada; prever recuo para encaixe dos pés na base do móvel, facilitando a aproximação dos usuários; dispor de iluminação junto ao móvel superior que favoreça a realização de tarefas de grande acuidade visual na bancada de trabalho; e planejar circulações e portas que favoreçam o acesso de cadeirante. No que se refere à realização de algumas tarefas na posição sentada, é importante que a cadeira ou o banco, caso sejam previstos, possam ser acomodados junto ao móvel da cozinha (por exemplo: sob a bancada), de forma a não constituir obstáculo à circulação, e que apresentem encosto para as costas e apoio para os braços.

A segurança foi outro atributo ambiental recorrente em três dos quatro métodos aplicados. Para que o ambiente e o mobiliário proporcionem segurança aos usuários recomendase: evitar cantos e quinas vivas, bem como formas cortantes (por exemplo, prateleiras com cantos pontiagudos), dando preferência a acabamentos arredondados ou cantos protegidos sempre que possível; utilizar materiais resistentes em todo o móvel (fechamentos, estruturas, ferragens), permitindo que o idoso se apoie nele sempre que necessário; dar preferência a puxadores aparafusados, e evitar o uso de puxadores colados, os quais podem soltar-se quando os idosos se apoiam neles; prever barras de apoio junto ao mobiliário e ambiente; posicionar fornos preferencialmente entre a altura do quadril e dos ombros; utilizar suportes próximos aos fornos que auxiliem na retirada de utensílios quentes, como prateleiras retráteis embutidas no móvel da cozinha; prever alerta sonoro e visual que auxilie os deficientes olfativos e auditivos sobre vazamento de gás e cheiro de fumaça; incorporar alguma forma de proteção junto à parte frontal de prateleiras, nichos e outros móveis abertos, que minimizem o risco de queda de objetos sobre o usuário.

A legibilidade foi outro atributo ambiental recorrente em três dos quatro métodos aplicados. Dentre os possíveis critérios e estratégias projetuais recomendados para sua implementação, incluem-se: explorar contraste e variação de formas, texturas e cores no ambiente ou mobiliário que auxiliem na percepção de seus limites, volumes e profundidades; evitar o uso associado de algumas cores de difícil distinção para idosos como o conjunto das cores azul, verde e roxo, bem como dos tons pastéis de azul, bege, amarelo e rosa, e a associação de tons de azul marinho, marrom e preto. A legibilidade inclui explorar outras formas de comunicar informações facilitando a compreensão da função de cada componente do ambiente. Por exemplo, podem-se utilizar recursos de comunicação visual como sinalização em braile - no caso de usuário cego - ou também imagens - no caso de usuário com perdas cognitivas relacionadas à memória - que informem o que há dentro de gavetas e armários, sem necessitar sua abertura.

Por fim, recomenda-se um bom aproveitamento do espaço disponível para o planejamento da cozinha, no sentido de incluir no projeto o máximo possível de áreas de armazenamento prateleiras, gavetas, estantes, etc. Tal recomendação é a única relacionada ao atributo funcionalidade. 


\section{Considerações finais}

O presente trabalho sintetiza critérios e estratégias projetuais que podem ser aplicadas no planejamento de uma cozinha residencial voltada para o público da terceira idade. Tendo em vista a escassez de publicações sobre o tema, acredita-se que a metodologia de Design Thinking permitiu esclarecer algumas das necessidades e anseios deste público específico.

Por meio da aplicação de diferentes métodos e técnicas, a metodologia do Design Thinking busca compreender necessidades, anseios e expectativas dos usuários favorecendo o desenvolvimento de um produto que lhes seja mais responsivo. Esta metodologia trouxe consigo diferentes formas de olhar para o mesmo público e de captar a informação, como a percepção ambiental de projetistas e de um geriatra, além da percepção e comportamento ambiental dos idosos. Acredita-se que os diferentes olhares sobre o tema contribuem sensivelmente para que se possa ter uma visão mais abrangente e completa, permitindo melhor compreender o público-alvo, as mudanças que decorrem do envelhecimento e os atributos significativos no planejamento deste ambiente específico.

Os atributos desejáveis ao planejamento de cozinhas para idosos que mais se destacaram foram: conforto, segurança, legibilidade e funcionalidade, e para eles, diversas alternativas projetuais foram sugeridas. Acredita-se que sua aplicação no planejamento de uma cozinha favorecerá o uso cotidiano pelo idoso e também pelos demais grupos usuários. Não se pretendeu, contudo, esgotar o tema. Certamente, com a aplicação de outros métodos e com uma amostra maior ou distinta, outros requisitos projetuais seriam evidenciados. Pretendeu-se apenas identificar alguns atributos e critérios projetuais passíveis de serem incorporadas no planejamento de cozinhas e que pudessem dar suporte ao usuário idoso.

Algumas das soluções sugeridas se direcionam a um perfil específico de usuários, como o cadeirante, cabendo destacar que nem todos os idosos se enquadrarão neste perfil e terão as mesmas necessidades. Assim, pretende-se que o material acima possa dar suporte ao planejamento desses ambientes, ao apresentar diferentes possibilidades projetuais, sem, contudo pressupor que todas elas deveriam ser incorporadas em uma única proposta. Além das especificidades de cada usuário, a incorporação das diretrizes projetuais mencionadas será determinada pela disponibilidade financeira do cliente, já que algumas soluções tem custo elevado, como a utilização de sistema de pistão para abaixar o móvel suspenso sempre que necessário. E por fim, a própria configuração espacial da cozinha dentro da residência (forma, área, esquadrias, posição de pontos de água, esgoto, eletricidade, etc.) será determinante na escolha das estratégias projetuais e no resultado final da proposta a ser desenvolvida.

Observa-se ainda haver pouca informação sobre as medidas antropométricas do idoso brasileiro. Assim, novos estudos na área de Ergonomia podem contribuir sensivelmente para ampliar o conhecimento sobre as características e necessidades desse público, seja aprofundando o tema do planejamento da cozinha ou de outros ambientes da residência. Esta parcela da população está em contínuo crescimento, e por ser um campo de mercado pouco explorado, torna-se um nicho promissor para designers desenvolverem mais pesquisas e projetos.

\section{Referências}

ABRAMS, William B.; BERKOW, Robert. Manual Merck de geriatria. São Paulo: Rouca, 1994. 
AMADIO, Alberto Carlos; SERRÃO, Júlio Cerca. Contextualização da biomecânica para a investigação do movimento: fundamentos, métodos e aplicações para análise da técnica esportiva. Revista Brasileira de Educação Física e Esporte, São Paulo, v.21, p.61-85, dez. 2007.

BARDIN, L. Análise do Conteúdo. São Paulo: Edições 70, 2011.

BRASIL. Presidência da República. Casa Civil. Subchefia para Assuntos Jurídicos. Lei no 10.741, de 10 de outubro de 2003. Dispõe sobre o Estatuto do Idoso e dá outras providências. Diário Oficial da União. Brasília (DF); 2003; 03 out. Seção 1, p. 1.

BRASIL. Ministério da Saúde. Envelhecimento e saúde da pessoa idosa. In: Cadernos de Atenção Básica n. 19. Brasília: Ministério da Saúde, 2006. (Série A. Normas e Manuais Técnicos).

CAMBIAGHI, Silvana. Desenho Universal: métodos e técnicas para arquitetos e urbanistas. São Paulo: Senac, 2012.

CHRISTENSON, Margaret A. Aging in the designed environment. New York: The Haworth Press, 1990.

DRECH, Dilvane; POMATTI, Dalva Maria; DORING, Marlene. Prevalência de acidentes domésticos em idosos residentes em uma área de abrangência da Estratégia de Saúde da Família. Revista Brasileira de Ciências do Envelhecimento Humano, Passo Fundo, v. 6, n. 1, p. 87-97, jan./abr. 2009.

DUL, Jan; WEERDMEESTER, Bernard. Ergonomia Prática. São Paulo: Editora Edgard Blücher, 2004.

FECHINE, Basílio R. A.; TROMPIERI, Nicolino. O processo de envelhecimento: as principais alterações que acontecem com o idoso com o passar dos anos. Inter Sciense Place, [s.l.], jan. 2012.

Disponível

em:

<http://ucbweb2.castelobranco.br/webcaf/arquivos/15482/10910/envelhecimento.pdf>. Acesso em: 15 dez. 2017.

FIGUEIREDO, Adma Hamam de. Brasil: uma visão geográfica e ambiental no início do século XXI. Rio de Janeiro: IBGE, 2016.

FRANK, Eduardo. Vejez: arquitectura y sociedad. Buenos Aires: Nobuko, 2003.

HAYFLICK, Leonard. Como e porque envelhecemos. Rio de Janeiro: Campus, 1997.

IIDA, Itiro. Ergonomia: projeto e produção. São Paulo: Blucher, 2005.

MATSUDO, S. M.; MATSUDO, V. K. R.; BARROS, T. L. N.. Impacto do envelhecimento nas variáveis antropométricas, neuromotoras e metabólicas da aptidão física. Revista brasileira de ciência e movimento, Brasília, v.8, n.4, p.21-32, 2000.

OLIVEIRA, Nielmar. IBGE: expectativa de vida dos brasileiros aumentou mais de 40 anos em 11 décadas. Rio de Janeiro, 2016. Disponível em: < http://agenciabrasil.ebc.com.br/geral/noticia/2016-08/ibge-expectativa-de-vida-dos-brasileirosaumentou-mais-de-75-anos-em-11> Acesso em: 08 dez. 2017.

PANERO, Julius; ZELNIK, Martin. Dimensionamento humano para espaços interiores: Um livro de consulta e referência para projetos. Barcelona: Editorial Gustavo Gili, 2002.

PORTAL BRASIL. Expectativa de vida no Brasil sobe para 75,5 anos em 2015. Brasília, 2016. Disponível em: <http://www.brasil.gov.br/governo/2016/12/expectativa-de-vida-no-brasil-sobe- 
para-75-5-anos-em-2015>. Acesso em 09 dez. 2017.

RHEINGANTZ, Paulo Afonso et al. Observando a qualidade do lugar: procedimentos para a avaliação pós-ocupação. Rio de Janeiro: Universidade Federal do Rio de Janeiro, 2009.

RIO, Rodrigo Pires do; PIRES, Licínia. Ergonomia: Fundamentos da prática ergonômica. São Paulo: Ltr, 2001.

SANOFF, Henry. Participatory Design: Theory and Techniques. North Carolina: North Carolina State University, 1990.

SERVIÇO DE PROTEÇÃO AO CRÉDITO - SPC. Consumo e uso do crédito na terceira idade. [s.I.], 2016. Disponível em: < https://www.spcbrasil.org.br/.../Análise-Consumo-de-Idosos-_-Uso-doCrédito.pdf >. Acesso em: 07 dez. 2017.

VIANNA, Maurício et al. Design thinking: inovação em negócios. Rio de Janeiro: MJV Press, 2012. 